\title{
Positiv eller problematisk propaganda?
}

\section{Att gå den breda linjen}

Ett reklamutskick utformat som en popcornkartong nådde i början av 2010 över 40000 skolungdomar i högstadiets nionde klass med ett erbjudande om gratis biovisning. Till mottagaren riktades en kortfattad appell som handlade om att följa med strömmen och samtidigt fundera över ett val med konsekvenser för den egna framtiden: "Gör som alla andra nior och gå på förhandsvisningen av Josef Fares nya film 'Farsan'. Film blir det, popcorn blir det, läsk blir det och givetvis blir det också helt fantastiskt." ${ }^{\prime 29}$ Längst ned i ena hörnet av reklambladet stod också att läsa: "NV är den bredaste linjen som ger behörighet till flest högskoleutbildningar." ${ }^{\prime 30}$

Utskicket ingick som en del av informationskampanjen "Den breda linjen" vars huvudsakliga ambition var att påverka elever som tänkt läsa samhällsvetenskaplig profil på gymnasiet att istället söka sig till en naturvetenskaplig inriktning. Vid tretton tillfällen runt om i landet, från Helsingborg i söder till Luleå i norr, visades film med tillhörande läsk och snacks märkta med kampanjens budskap. Biobesöket inleddes med ett längre reklaminslag för naturvetenskapligt program där lärokursens förtjänster presenterades. Den allt överskuggande förkunnelsen var att detta program garanterade störst valfrihet inför framtiden. Efter filmen försågs eleverna med ytterligare material. I foajéerna delades det ut påsar innehållande information om naturvetenskapligt program, men också NV-märkta kortlekar med texten på bredden och NV-tröjor i extra tilltaget format. ${ }^{631}$

Bakom projektet stod Teknikdelegationen som tillsatts av regeringen i en strävan att öka skolelevers intresse för naturvetenskapliga och tekniska utbildningar. Kampanjen syntes även på gymnasiemässor där eleverna kunde spela pingis på bredden och ta del av information i utstuderat breda soffor. Astronauten Christer Fuglesang, nyligen hemkommen 
från rymden, närvarade vid flera evenemang och talade om sin tid som naturvetenskaplig gymnasiestudent. Fuglesangs deltagande var avsett att förkroppsliga tanken på "goda karriärmöjligheter på en lysande arbetsmarknad" - i en vidare mening skulle hans närvaro sprida en på samma gång blågul och internationell strålglans över delegationens existens. ${ }^{632}$

Denna bok har haft millennieskiftet som bortre gräns för analyser och sammanfattningar. Ändå kan inslaget från 2010 tillåtas tjäna som ögonblicksbild för livskraften hos ett fenomen som överskrider de periodiseringar historiker ofta tvingas upprätta. "Den breda linjen" understryker med vilken kontinuitet naturvetenskaplig och teknisk rekryteringspolitik etablerat sig som ett självklart samhälleligt inslag under efterkrigstiden. Genom olika åtgärder - utformade som stora nationella kampanjer och små lokala initiativ, inom och utanför skolan, med en stor variation i tilltal och utförande - har en mängd individer inom utbildningssystemet blivit uppmuntrade, uppmanade, vägledda och påverkade att välja yrken och utbildningar med inriktning mot naturvetenskap och teknik.

Jag har visat att rekryteringsfrågans framväxt i efterkrigstidens samhälle bottnade i flera utvecklingar. En av dem var de behovsprognoser för naturvetare och ingenjörer som lades fram i såväl internationella sammanhang som på svensk mark med början under 1950- och 1960-talen. Krigsåren och den närmast efterföljande tiden hade sett en ny värdering av vetenskaplig forskning och tillämpning, både från de militära och civila delarna av samhället. Inte minst fanns en uppfattning om ett tydligt samband mellan vetenskap och teorier om ekonomisk tillväxt. Humankapitalteorins breda genomslag och tanken på en förädling av arbetskraften gjorde att utbildning successivt fogades in i denna matris.

Men anledningarna till rekryteringstematikens stadigvarande närvaro står inte endast att finna i synen på teknisk utbildning som en investering för ekonomisk progression. Även om sådana motiv på många sätt var en förutsättning för den linjära modell som antagits leda från naturvetenskaplig och teknisk utbildning till ekonomisk tillväxt, tillkom det under följande decennier kontinuerligt nya motiv för fler naturvetare och ingenjörer. Ovan har jag visat hur argument som anknöt till miljö, jämställdhet och vetenskaplig medborgarbildning 

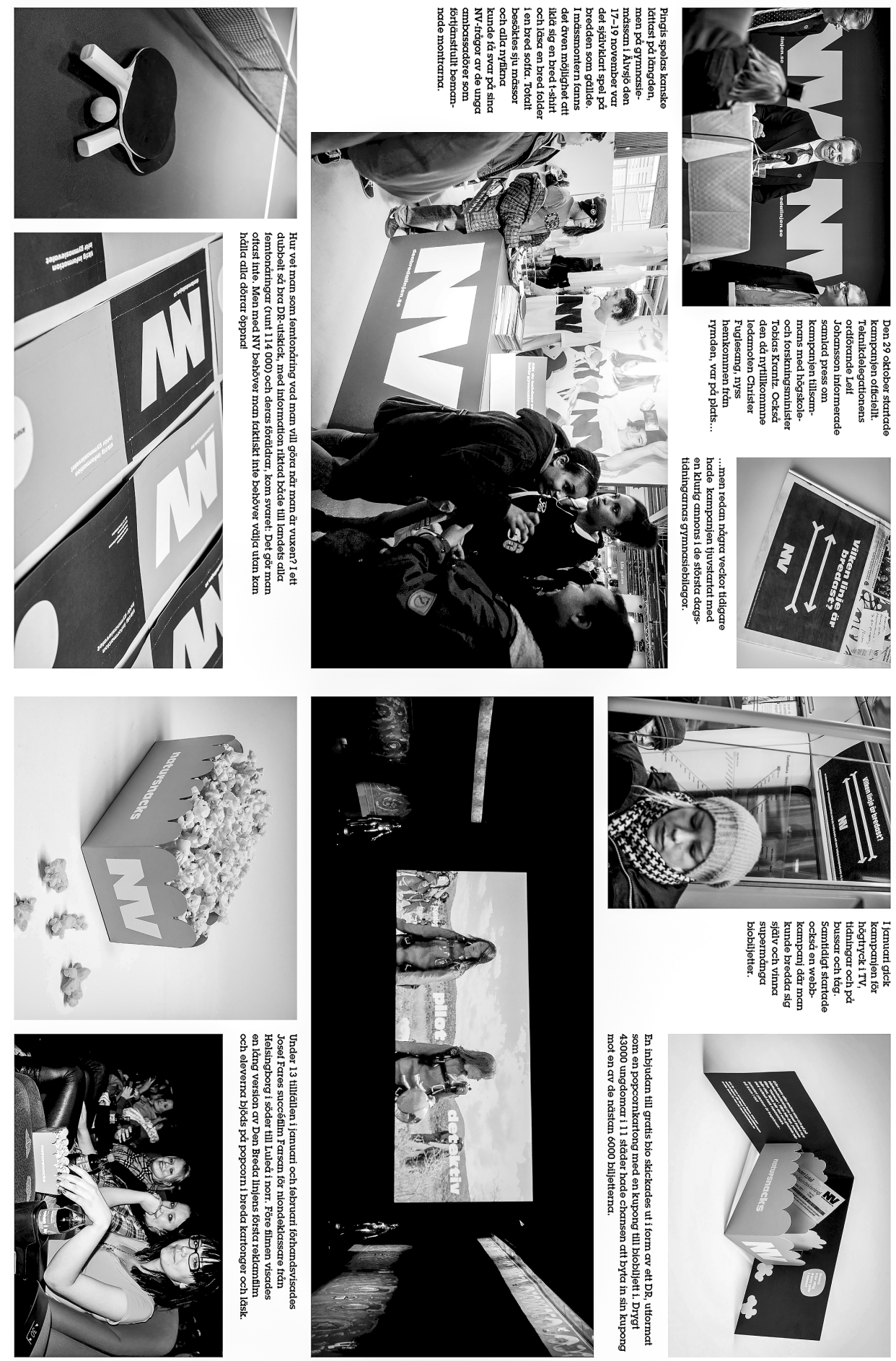
ökade den innehållsliga styrkan i rekryteringspolitiken. Detta gav den en större närvaro på ett intellektuellt och retoriskt plan, men skapade också nya samhälleliga ytor och framväxten av konkreta enrollerande praktiker. Alla ovanstående argument finns kvar i dagens diskussion och utgör en påminnelse om med vilken konstans ansträngningarna för ökad tillströmning till naturvetenskap och teknik kommit att närvara i samtidens samhälle.

Ytterligare en orsak till framväxten av rekryteringspolitiken kan sökas i dess förhållande till berättelser om en nation, en ekonomi eller en kultur. Problemområdet växte fram parallellt i Sverige, USA och många andra länder i främst västvärlden. Som en konsekvens kom den att präglas i sitt utförande av respektive nations kulturella självbilder. Medan exempelvis den amerikanska enrolleringstematiken på ett påtagligt sätt tog intryck av kalla kriget, formades den svenska av en vilja att bygga det moderna folkhemmet och ett välfärdssamhälle. Men det svenska talet om fler naturvetare och ingenjörer hämtade också näring ur en djupt rotad föreställning om vårt lands fallenhet för tekniska och snillrika uppfinningar, vilket genererade en omfattning på politiken som blev mer betydande än i flera andra länder.

I studien har jag också haft ambitionen att påvisa konsekvenser av rekryteringsambitionerna. Jag har vägletts av en vilja att lyfta fram andra följder och effekter än de planerade. Således har jag anlagt ett perspektiv som till stora delar avviker från de historiska aktörernas visioner om naturvetenskap, teknik och utbildning. Detta har jag gjort genom analyser i huvudsak förankrade i två forskningsområden: dels studier som berör naturvetenskapernas utbildningshistoria, dels styrningsmentaliteter. Genom att luta mig mot det förstnämnda har jag velat se olika rekryteringsåtgärder som uttryck bland annat för en politisering av det naturvetenskapligt-didaktiska objektet. Både som idé och praktik började lärande av naturvetenskap och teknik under efterkrigstiden ta allt starkare intryck av befolkningspolitiska idéer om antalet och andelen individer inom olika yrken. Detta gav utbildningarna nya uppdrag med vilket följde ökad uppmärksamhet och större resurser men också andra typer av förväntningar. Även om förbindelser mellan didaktik och politik varit historiskt rotade i äldre praktiker, framträdde de nu i en på många sätt ny skepnad. Dessutom materialiserade de sig i nya former - inte bara i traditionella undervisningsmiljöer utan även i så vitt skilda exempel som utställningar, studievägledning och tävlingar. 
I den meningen kan resultaten av min studie vara betydelsefulla för att förstå vetenskapens förändrade villkor i efterkrigstidens samhälle. Utbildningssamhället är en fundamental del av de strukturer som på olika sätt präglar vetenskapens återväxt, vare sig det sker vid mellanstadiets första laboratorietillfälle eller på utbildningen i teknisk fysik vid högskolorna. Det är i det ljuset jag velat betrakta den rekryteringspolitik som riktats mot nya generationer och som resulterat i innovationer, både som idéer och som materialiteter i form av byggnader, läroböcker och fysiska förebilder.

När det gäller det andra forskningsområde som influerat studien kan det vara på sin plats att för ett kort ögonblick återvända till "Den breda linjen". Kampanjen förvaltade alldeles uppenbart ett tillvägagångssätt som grundlagts av 1900-talets bärande politiska idéer om relationen mellan individ och samhälle. Tilltalen som nådde ungdomarna via tröjor, kortlekar, mobilapplikationer och pingisbord framställde det som förnuftigt att välja en utbildning som garanterade största möjliga valfrihet. Då naturvetenskapliga utbildningar sedan tidigare framställts som synonyma med just sådana värden hade kampanjen som föresats att "stärka och sprida, en redan existerande attityd". ${ }^{63}$

Men idén om individens valfrihet och målet att utexaminera fler i de önskade yrkesgrupperna var inte en okomplicerad kombination. I mitten av 1960-talet omgavs det nya gymnasiet av förväntningar på att skolungdomar omgående skulle lockas att söka sig till naturvetenskap och teknik. Utbildningarna fylldes med löften om en ljus framtida arbetsmarknad. Därutöver rymde de i hög utsträckning den tidiga efterkrigstidens tro på vetenskapens betydelse för samhällets modernisering och - åtminstone när det gällde teknikutbildningarna - individens emancipation från klassamhället.

Förväntningarna på skolungdomens beteendemönster kom dock inte att infrias. Istället blottlades en problematik som fanns i ambitionen att samtidigt tillgodose kraven på vetenskap och valfrihet för det moderna välfärdssamhällets förverkligande. Den lösning som efter hand blev alltmer tydlig vägleddes av tanken på att individen själv måste fås att uppfylla den politiska drömmen och göra det önskvärda valet till sitt eget beslut. I denna strävan förenades en mängd olika aktörer som med riktade åtgärder sökte påverka elever att överta den uppfattning de själva företrädde. Som en konsekvens menar jag att en helt ny form av maktutövning uppstod som inte funnits tidigare och som var helt avhängig de mål som uttrycktes i efterkrigstidens rekryteringsambitioner. 
Inte minst tog sig denna maktutövning uttryck genom olika former av delaktighet och självstyre som fanns inbäddade i många enrolleringspraktiker. Även i det avseendet framstår Teknikdelegationens strategier som en förlängning av de riktlinjer som formats under 1900-talets andra hälft. "Den breda linjen" utgick på många sätt från individernas olika former av inblandning. Som en del av satsningens framgång betonade Teknikdelegationen hur stor spridning kampanjen hade fått, både fysiskt och digitalt. Genom en diversifierad flora av mediematerialiteter i form av kläder, föremål, hemsidor och personer förmåddes ungdomarna att vidareförmedla budskapet. ${ }^{634}$ På så sätt skulle de själva komma att bli en del av kampanjen. I det avseendet gav Teknikdelegationens initiativ prov på delaktighetens både didaktiska och politiska funktioner. De självteknologier som innebar inhämtandet av kunskap och makttagandet över sin egen utbildning var på så sätt samtidiga med utförandet av vissa önskvärda handlingar eller utvecklandet av vissa specifika beteenden.

I min undersökning har jag också visat hur praktiserandet av rekryteringspolitiken vid några tillfällen gav upphov till friktion och motstånd. När tillvägagångssättet framstod som för forcerat hotades just de värden som var avsedda att förknippas med naturvetenskap och teknik - ökade möjligheter och större valfrihet. I dessa situationer visade sig de outtalade gränserna för fenomenets genomförbarhet, markerade av det demokratiska samhällets självbild.

Även om dessa tillfällen var relativt fåtaliga under undersökningsperioden gav de varje gång upphov till ett slags självkorrigering och anpassning till vad som uppfattades vara möjligt att säga och göra. Sådana tillfällen har aktualiserat frågan om de etiska aspekterna av den positiva propagandan för naturvetenskap och teknik. Intresset för den typen av spörsmål har dock aldrig varit omfattande och tycks dessutom ha minskat när vi närmar oss vår egen samtid. En talande formulering kan hämtas från Matematikdelegationens slutrapport Att lyfta matematiken som lämnades till regeringen 2004. Delegationen konstaterade i en passage att det ibland kan uppstå målkonflikter i utbildningssystemet:

Å ena sidan finns ett ekonomiskt betingat samhällsmål som kräver att fler ungdomar väljer att studera matematikintensiva utbildningar. $\AA$ andra sidan vill samhället också att ungdomar i frihetens namn skall få välja vad de vill studera. Uppenbarligen leder detta fria val idag inte 
till resultat som statsmakterna önskar. Förbättrade insikter skulle leda till att båda målen kan nås. ${ }^{635}$

Uttalandet blottlägger en tolkning av konflikterna där lösningen framförallt antas ligga i mer information och kunskap om problemområdet, men där målsättningen fortfarande är densamma. Förutom att en sådan utsaga illustrerar det liberala styrets rationalitet, bekräftar den också den mer än halvsekelgamla uppfattningen att realiserandet av valfrihetens samhälle fordrar att tillräckligt många av medborgarna visar upp ett specifikt beteende.

I förlängningen av denna slutsats är det möjligt att hävda att min studie ger fördjupade insikter i de förbehåll som varit behäftade med det moderna samhällets förverkligande. Parollen "valfrihetens samhälle" som från början dominerats av socialpolitiska visioner om den enskildes rätt att välja utbildning har efter hand fyllts med villkor på särskilda handlingsmönster hos unga människor där val av naturvetenskap och teknik betraktats som synonyma med fortsatt modernisering, ökad sysselsättning och högre jämställdhet, men också med större meningsfullhet i den enskildes yrkesutövning, goda möjligheter till personlig karriär och fortsatta valmöjligheter i utbildningssystemet. Mitt arbete knyter härmed an till andra undersökningar av styrningsmentaliteter under efterkrigstiden som visat på att frihet har använts för att påverka människors handlande i bestämda riktningar. Detta gäller både med avseende på det specifika forskningsområdet naturvetenskapernas utbildningshistoria som på ett mer allmänt definierat fält med intresse för hur organiserandet av individers handlande under tidigare perioder influerats av idéer och praktiker för fostran och utbildning. ${ }^{636}$

\section{Säkra siffror?}

Vad som också kommit till uttryck i min genomgång är att ungdomars förhållande till naturvetenskap och teknik på flera sätt har länkats samman med bredare kulturyttringar och på så sätt gett upphov till tolkningar av både samtiden och det förflutna. Vid sidan av det svenska narrativet om en hotad ingenjörs- och uppfinnartradition ledde exempelvis rekryteringsbekymren på europeisk unionsnivå till ett sökande i kontinentens historia efter essentiellt grundade orsaker till problemet. Eventuella sådana bedömdes kunna förklara den utbredda vetenskapsskepsis som 
organisationen menade sig ha identifierat i sina medlemsländer. På global nivå hade överstatliga aktörer som OECD sammanträffat med företrädare för japanska och amerikanska regeringar och forskningsråd för att ta upp rekryteringen till naturvetenskap och teknik som ett globalt eller åtminstone inom hela västvärlden existerande problem. I dessa sammanhang antogs många av den post-industriella världens länder var lika hårt drabbade och i behov av liknande lösningar.

Tillsammans har dessa olika uttalanden om problembilden tecknat en bild av polariserade samhällen där stat, näringsliv och ett stort antal andra aktörer stått på en sida och bejakat naturvetenskap och teknik. På den andra har ungdomarna återfunnits, vilka år efter år uppfattas vara oengagerade och skeptiska inför samma fenomen. Föreställningen om de yngre generationernas avståndstagande har på så sätt gjorts till ett kännetecken och ett tidstypiskt symtom på västerlandets oförmåga att kommunicera vetenskap på rätt sätt.

Identifierandet av ett ungdomens motstånd mot vetenskapen har till stor del vilat på statistiska rapporter, beräkningar och prognoser om framtiden. Vad som framkommit i min undersökning är dock att siffrorna vid ett flertal tillfällen visat sig vara tveksamma och mer än en gång blivit korrigerade i efter hand. Kortsiktiga nedgångar för naturvetenskapliga och tekniska utbildningar har visserligen kunnat beläggas med statistik, men har också visat sig följa allmänna tillbakagångar i söktryck eller vara isolerade kriser inom utbildningssystemet utan betydelse för en redan mättad arbetsmarknad. Det osäkra underlaget gör att de bredare penseldragen i bilderna av ungdomars förhållande till vetenskap - bilder av skepsis, ointresse och avståndstagande - framstår som svagare underbyggda.

I boken Falling Behind? gör den amerikanske demografiforskaren Michael Teitelbaum en genomgång av den tekniska och naturvetenskapliga rekryteringsfrågans konsekvenser i USA under den andra halvan av 1900-talet. Han visar att larmrapporter liknande de i Sverige vid flera tillfällen genererat stora krav på satsningar för att öka utbildningen av naturvetare och tekniker. Teitelbaum pekar dock på den rikliga förekomsten av felaktiga prognoser under perioden och det stora inflytande som dessa haft över politiska beslut. I cykler om tre faser har rekryteringspolitiken ofta upprepat sig genom att i ett första läge slå larm om bristen på de eftertraktade yrkesgrupperna, i fas två innehålla politiska satsningar för att öka antalet, medan fas tre innebär 

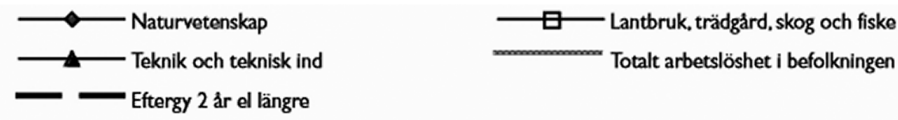

Procent

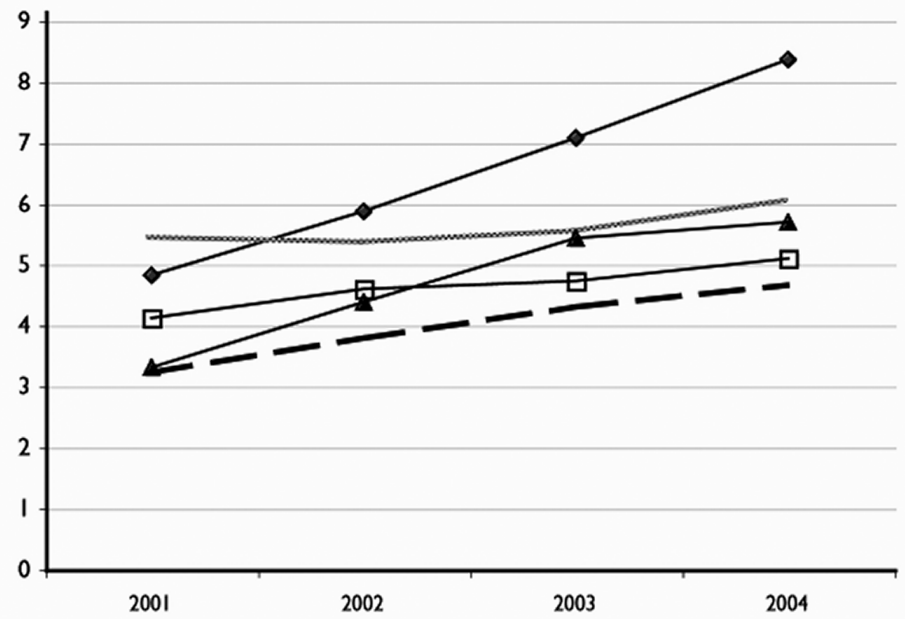

Bild 25. Arbetslösheten under 2000-talets första år var högre bland naturvetare (och tekniker) än övrig utbildad befolkning. (Bildkälla: AMS)

att ett stort antal nyutbildade individer möter en sval arbetsmarknad utan goda karriärvillkor. ${ }^{637}$

Teitelbaums studie ger perspektiv på den amerikanska utvecklingen, men visar också möjligheterna att ringa in den vetenskapliga rekryteringsfrågans historiskt specifika förutsättningar och stora beroende av siffror. Att på så sätt historisera uppkomsten av en problembild ger möjlighet att analysera dess följder för framskrivandet av en ny politik som till stora delar handlar om utbildning, ekonomi och sysselsättning.

Rekryteringspolitiken har haft problematiska konsekvenser även för den svenska arbetsmarknaden. Ovan har jag visat att högt uppdrivna prognoser under 1970-talet indikerade stora behov av naturvetare. Bedömningarna visade sig senare stämma dåligt överens med den faktiska arbetsmarknaden som snarare gav intryck av att vara mättad. En liknande problematik visade sig under de första åren av 2000-talet. I sin rapport Sverige behöver fler naturvetare - eller? skrev Högskoleverket att arbetslösheten var högre bland naturvetare och teknikutbildade än 
i hela populationen med en eftergymnasial utbildning på minst två år. För nyutexaminerade naturvetare framställdes situationen rentav som "mycket svår". ${ }^{638}$ Högskoleverket slog också fast att detta bland annat berodde på att de uppgifter som gick ut från enskilda lärosäten ibland var otillräckliga. Utifrån en genomgång av hur utbildningar i naturvetenskap presenterats konstaterade myndigheten att informationen hemföll till en önskan att rekrytera studenter snarare än att ge saklig information om förhållandena på arbetsmarknaden. ${ }^{639}$

Något som ytterligare förenar Falling Behind? med min studie är att de tillfällen då statistiken i efter hand visat sig vara missvisande - under 1970-talets "naturvetarkris" eller det tidiga 1990-talets ingenjörsbrist - inte haft några synbara konsekvenser för den planerade politiken. Åtgärder och praktiker har fortsatt att finansieras utifrån samma bevekelsegrunder som tidigare. Situationen utgör en bekräftelse på den diskursiva styrkan i problembilden och understryker dess karaktär av ett slags permanent symtom på samtiden. Den ursprungliga berättelsen har på så sätt förts vidare under efterkrigstiden och etablerat bilden av ett normaltillstånd för Sverige, Europa och västvärlden.

\section{Rekryteringspolitikens historielöshet}

I bokens inledning påtalade jag att den naturvetenskapliga och tekniska rekryteringspolitiken ofta präglats av en historielöshet. Med det uttrycket avsåg jag en frånvaro av historiskt grundade ansatser att förstå fenomenet - dess formering som samhälleligt problemområde, dess utgångspunkter för politiska åtgärder, men också dess konsekvenser i efterkrigstidens samhälle. Detta innebär inte att tillbakablickar på tidigare perioder helt saknades. Som tidigare nämnt förekom det att viktiga programtexter och strategiska dokument ibland återvände till föregående decenniers initiativ. I genomgångar av tidigare projekt konstaterades att det olösta problemet hade ärvts i generationer av politiker, tjänstemän och organisationer. Ett historiebruk som knöts till rekryteringen är också möjligt att identifiera i berättelserna om Sveriges förflutna som en teknik- och vetenskapsnation, någonting som ökat den dramaturgiska effekten av samtidens svårigheter.

Men dessa hågkomster har endast fungerat som en bekräftelse på den förda politikens giltighet och knappast alls gett utrymme för inslag av mer historiskt reflekterande eller problematiserande karaktär. Frågor om rekryteringsbehovets ursprung, grundläggande premisser och följder 
har i förlängningen blivit osynliggjorda. Sannolikt har de bedömts som ointressanta att besvara då de haft så lite att göra med problemets lösning.

I jämförelse med dessa återblickar är det en annan historia jag velat skriva. Jag har velat lyfta fram förutsättningarna för rekryteringsfrågans formering och förmåga att bibehålla sitt problemformuleringsinitiativ även när mycket har talat emot det. Därutöver har jag drivits av en vilja att peka på dess konsekvenser bortom de historiska aktörernas egna målsättningar att åtgärda problemet. Exempel på sådana konsekvenser är den ökande närvaron av naturvetenskapligt och tekniskt utbildande institutioner i samhället, den allt större politiseringen av lärande inom dessa discipliner, liksom de nya maktförhållanden som i kölvattnet av rekryteringspolitiken etablerats mellan samhällets auktoriteter och dess individer.

Även om min strävan har varit att kritiskt historisera rekryteringspolitikens sanningar och förgivettaganden, vill jag inte förneka att behovet av dessa yrkesgrupper kan vara betydande i perioder eller påstå att samhället inte skall sträva efter att utbilda personer i teknik och naturvetenskap. Gemensamt formade mål som fastslagits för samhällets bästa, däribland teknikutveckling, forskning, sysselsättning, miljövård, medborgarbildning och jämställdhet, förutsätter i högsta grad att vi har tillgång till dessa yrkesgrupper och kunskaper.

Men i rekryteringsambitionerna har det ofta saknats ett självkritiskt förhållningssätt - bland politiker, näringslivets företrädare, intresseorganisationer och inom naturvetenskapernas didaktik. Är det alltid rimligt att avsätta delar av samhällets tillgångar - både ekonomiska och personella - till att propagera för vissa utbildningar och yrken, trots att insatserna vid återkommande tillfällen har visat sig bygga på osäkra underlag? Hur asymmetrisk kan en påverkansprocess tillåtas vara i ett utbildningssamhälle som samtidigt strävar efter en balans i informationsutbudet? Bör inte de processer som föregår beslut om ingenjörskampanjer redovisas mer öppet och problematiserande?

I en tid som mer än någonsin tidigare gör bruk av ordet valfrihet är det nödvändigt att frågan om den positiva propagandans etik åter börjar ställas. Inte för att den enkelt låter sig besvaras, utan för att den inte gör det. 